\title{
DA CONCEPÇÃO À PRÁTICA DE FORMAÇÃO INICIAL: A EJA no currículo de pedagogia
}

\author{
Jane Paiva \\ Fátima Lobato Fernandes ${ }^{(*)}$
}

\section{ANTECEDENTES}

A formação inicial em Pedagogia, como concebida após a normatização do Conselho Nacional de Educação (CNE) em 2005, orientou e estimulou cursos em todo o país a reverem suas ofertas, tendo como fundamentos concepções e princípios orientadores do documento legal. Neste artigo, trataremos de um processo de formação inicial em universidade pública estadual, a Universidade do Estado do Rio de Janeiro (UERJ), especificamente destacando a produção de um campo de conhecimentos que tem sujeitos jovens e adultos não escolarizados como público dessa formação, desde o início da década de 1990, e os movimentos que ocorreram em torno desse campo e que impulsionaram a constante revisão do como fazer a formação que inclui sujeitos de direito antes não contemplados na pedagogia nem em magistério de ensino médio.

Na UERJ, a história da formação inicial incluindo o campo da educação de jovens e adultos teve motivação e origem na Constituição Federal de 1988, ao preceituar e garantir o direito de todos ao ensino fundamental independente da idade. Um coletivo de professores discutiu por três anos, até a implantação, uma nova proposta de curso de pedagogia. $\mathrm{O}$ curso voltou-se para a docência na educação infantil (EI), na educação de jovens e adultos (EJA), na educação especial (Ed. Esp.) e para a área do magistério das matérias pedagógicas - atribuição de professores de cursos normais para a formação de magistério em nível médio. Cada área compunha uma habilitação, admitindo-se a possibilidade de serem feitas até duas áreas em concomitância, sendo obrigatório, nesse caso, que uma delas fosse a de matérias pedagógicas, pelo entendimento de que o especialista de um campo

\footnotetext{
${ }^{(*)}$ Jane Paiva. Professora do Programa de Pós-graduação em Educação (ProPed) e da Faculdade de Educação da Universidade do Estado do Rio de Janeiro (UERJ). Pesquisadora na área de educação de jovens e adultos, atuando principalmente nos temas de pesquisa: educação de jovens e adultos, políticas públicas de alfabetização, de educação de jovens e adultos, de educação continuada e aprendizagem ao longo da vida, educação em prisões, leitura e escrita, formação de pedagogos e de professores para o campo da educação de jovens e adultos e formação continuada. Currículo: <http://lattes.cnpq.br/3049044829510326>.
}

Fátima L. Fernandes. Professora da Faculdade de Educação da UERJ. Pesquisadora na área de educação de jovens e adultos, atuando principalmente nos temas de pesquisa: alfabetização, formação continuada de professores da EJA, educação de jovens e adultos, questões raciais, política de educação inclusiva e direito à educação. Coordena cursos de extensão na área de formação continuada de professores que atuam na educação de jovens e adultos das redes públicas de ensino e no campo de gestão educacional. Currículo: <http://lattes.cnpq.br/5894241244939473>. 
poderia tratá-lo na formação de professores de nível médio. Um núcleo básico de disciplinas conformava o percurso comum até o sexto período para, em seguida, ocorrer a escolha do campo, o que significava cursar por dois semestres disciplinas específicas de educação infantil, de educação de jovens e adultos, de educação especial, além de outras cuja interseção exigia visão mais ampla do campo estudado, como era o caso de Alfabetização I e II.

Implantado em 1991, o desenho seguiu até 2002, embora no curso dessa década algumas alterações já viessem sendo efetivadas na prática da formação, especialmente após a V Conferência Internacional de Educação de Adultos (V Confintea, 1996), quando se consolidava a educação de adultos para além da escolarização, como assumida entre nós, mas, especialmente, pela perspectiva de educação ao longo da vida/educação continuada.

A proposta curricular com habilitação para a EJA partiu do pressuposto de que havia, na prática social, um largo campo de atuação para o professor de primeira a quarta séries ${ }^{1}$ do ensino fundamental de jovens e adultos. Por isso mesmo, sua formação precisava estar garantida, porque os sujeitos de direito não eram apenas crianças, mas todos os cidadãos brasileiros, independente da idade. Isso requeria disciplinas vinculadas ao campo e à prática de ensino específica na composição do currículo do curso, o que se aliava a dois semestres de estágio produtivo precedendo o momento da escolha quanto à habilitação a ser seguida, visando a um primeiro contato com projetos de pesquisa ou de extensão de algum desses campos organizados, oferecendo uma prévia da experiência.

Havia, entretanto, um outro movimento que a V Confintea ensejava, o que significava dizer que a formação na pedagogia não podia restringir-se à condição do magistério, mas incluir a de pedagogo também, considerando as múltiplas ações/intervenções que muitas organizações não governamentais (ONGs) executavam junto à sociedade e que, em maioria, tinham sujeitos jovens e adultos como público primordial. Não eram, em grande parte, ações escolares, mas ações educativas, ${ }^{2}$ voltadas à consciência de direitos humanos; da necessidade de manter outra relação com o ambiente e com relações de gênero e étnico-raciais; de compreender e apreender recursos da comunicação e da mídia, utilizando-se deles para produzir versões da história de grupos sociais fora da oficialidade que até então sempre os representara; enfim, eram ações que partiam de princípios caros às formas como aprendem jovens e adultos, e que extrapolam perspectivas escolares, para se fazerem novos projetos, novas metodologias, novas práticas sociais.

\footnotetext{
${ }^{1}$ Esta era a nomenclatura adotada à época, hoje correspondendo do $1^{\circ}$ ao $5^{\circ}$ anos do ensino fundamental.

${ }^{2}$ Fazemos distinção entre ações educacionais e ações educativas. A primeira, ligada a ações que se realizam no interior do sistema educacional; a segunda, como a que ocorre em práticas sociais que educam/formam os sujeitos.
} 
Como esta dimensão da formação não fora pautada na reformulação do curso, paulatinamente foram sendo introduzidos novos campos de compreensão pela prática de ensino, e alargando as possibilidades de atuação profissional de pedagogos, desafiados a assumirem espaços de trabalho que requeriam esses profissionais, tanto para a formulação e implementação de projetos, quanto para a captação de recursos, principalmente, em agências internacionais, o que permitiria intervir com variados desenhos de projetos, e com êxito, na realidade brasileira.

Paralelamente às discussões primeiras sobre a reformulação do curso de Pedagogia, ocorria também na Faculdade de Educação um outro debate, com a Prefeitura da cidade do Rio de Janeiro. Uma assinatura de convênio de cooperação mútua definia que a UERJ ofereceria, aos professores da rede municipal, cursos de extensão como formação continuada e um curso de graduação de licenciatura plena de magistério das séries iniciais do ainda primeiro grau. $O$ ineditismo da proposta, à época - que se antecipava à perspectiva fixada posteriormente na Lei de Diretrizes e Bases da Educação Nacional (LDBEN, 9.394/1996) de formação de professor para os anos iniciais do ensino fundamental em nível superior - mobilizou a secretaria municipal de educação e a Universidade, em várias unidades acadêmicas de formação de professores, intra e extra-campus central. Superadas as dificuldades iniciais, o curso foi aprovado e realizou o primeiro vestibular em julho de 1991. Extinto em 1995 o convênio com a secretaria municipal, por razões de não cumprimento do acordo firmado, o curso abriu-se à comunidade em geral, preservados seus pressupostos e estrutura curricular.

Convivia-se, assim, com dois cursos paralelos de formação para o magistério - um de professores de primeira a quarta séries e outro de Pedagogia, com habilitações para EI, EJA, Ed. Esp. e matérias pedagógicas, o que coexistiu até 2003, quando da implantação de outra concepção, apresentada adiante.

$\mathrm{O}$ movimento preparatório à V Conferência Internacional de Educação de Adultos (V Confintea, 1997) fez com que novos conteúdos e significações se dessem a conhecer, vivenciados pela participação direta e escuta sensível de professores da Universidade que participaram das ações decorrentes desse momento. Do mesmo modo, a promulgação da LDBEN em dezembro de 1996 configurou outro marco fundamental.

Todos esses movimentos geraram um fazer formativo para a EJA sintonizado com necessidades das populações, que ultrapassavam os limites da escola. Espaços educativos, de múltiplas aprendizagens na prática social eram campo de atuação - e de redescobrimento - dos futuros pedagogos. Passava-se, pois, a desafiar a formação do graduado em pedagogia, de quem se exigia atuação em espaços sociais que lidavam com direitos - ambientais, humanos, civis, de 
gênero, étnicos, à diversidade, à ruralidade, à cidade, à juventude etc. -, tanto em apoio à luta de movimentos sociais, como em ações de organizações não governamentais, de entidades filantrópicas, de organizações governamentais - autarquias, fundações, museus, empresas formadoras de sujeitos para o trabalho que desenvolvem, habitualmente denominados recursos humanos, no modelo capitalista.

A prática da formação, então, se transformava: o campo do estágio se alargava para além de projetos de alfabetização ou da escola de educação de jovens e adultos, abarcando novas possibilidades, em muitas instituições. O pedagogo formado precisava compreender, ler criticamente e interferir nessas variadas possibilidades, fundamentado em princípios que sustentavam a área, para produzir, segundo especificidades das instituições que educam e de seus sujeitos, um projeto de intervenção pedagógica adequado aos objetivos de cada ação proposta. Não se formava, apenas, o professor de EJA, mas um pedagogo capaz de formular, gestionar, monitorar e avaliar projetos de educação de jovens e adultos, na dimensão do significado do aprender por toda a vida.

Muitos foram os pedagogos formados por esse desenho de curso. O que em nenhum momento significou mudança no modo como os sistemas de ensino promoveram concursos públicos, reservando vagas específicas para professores de EJA, quando dispunham de oferta na rede. Nossos ex-alunos ingressavam nos sistemas pelo que estes ofereciam - concursos para professores de primeira a quarta séries do ensino fundamental -, e começavam a carreira, frequentemente, trabalhando com crianças. Familiarizados com os meandros da carreira e os remanejamentos internos do sistema, chegavam à EJA, qualificando o sistema, mas vivendo, muitas vezes, fortes embates com companheiros de escola, diretores e equipe técnica de secretarias de educação, em defesa de projetos pedagógicos mais adequados ao público dessas escolas.

Nenhum estudo longitudinal foi realizado com esses egressos, acompanhando carreiras, atuações profissionais, vínculos com o campo. Há que se considerar que a demanda potencial por esse profissional é imensa, face ao número de pessoas não escolarizadas no ensino fundamental em diferentes momentos do percurso. No plano da realidade, entretanto, tem-se uma oferta de trabalho não compatível em número com a demanda potencial de escolarização que, ao contrário do esperado, não cresce em número de matrículas, mas decresce ano a ano, principalmente pelo fechamento de classes e escolas, em descumprimento flagrante do dever do Estado.

Até 2003 esse modelo foi adotado, quando um novo desenho, concebido após quase três anos de discussões, passou a regular o curso de pedagogia. Nesse momento, iam longe as discussões levadas a cabo pela Associação Nacional pela Formação dos Profissionais da Educação 
(Anfope), quanto ao que deveria ser um curso de formação de professores em nível superior, e a participação de muitos professores pesquisadores nesse espaço aportaram valiosas contribuições ao novo currículo, mesmo antes de as diretrizes curriculares da pedagogia serem homologadas pelo Ministério da Educação (MEC).

\section{EXPANSÃO DA CONCEPÇÃO HISTÓRICA DO CURSO DE PEDAGOGIA - DISPUTAS DE CAMPOS DE SABERES E DE FORMAÇÃO}

A docência como base da formação do educador foi o princípio assumido para a formação do pedagogo, concebida como tarefa social, historicamente situada, comprometida com a maioria da população e com questões relevantes da educação e da sociedade. A intervenção pedagógica exigia um pensamento crítico forjado no centramento da unidade teoria prática e no que Freire (passim) reitera como capacidade de denunciar e anunciar: denúncia dos problemas e estímulo à capacidade de propor mudanças - o anúncio.

A perspectiva dialética da educação se anunciava na formulação do curso, o que significava pensá-lo como totalidade, admitir contradições e a possibilidade de transformar a realidade e a relação teoria prática. Intentava-se conciliar a formação técnica com a formação política, complementarmente, em que esta última implicava a compreensão sobre quando e como intervir na realidade social que cerca o fazer do pedagogo.

Elementos da conjuntura, articulados pela compreensão metódica de aspectos contraditórios do contexto socioeconômico e cultural poderiam levar à produção, ao desenvolvimento e à crítica de políticas voltadas à escola pública; à valorização de atividades pedagógicas; e ao aprofundamento de relações entre comunidades externas e internas à Universidade, com vista à criação de novos e possíveis percursos, assim como à socialização do saber. Conquistas técnico científicas compartilhadas no cotidiano e vinculadas à participação mais estreita de sujeitos que aprendem a partir de repertórios próprios, definiam o movimento solidário de repartição do conhecimento, como ato político fundamental.

Ampliada a concepção de prática educativa e estendida a diferentes espaços da sociedade para além do âmbito escolar estabelecia vínculos da educação com práticas sociais e culturais, pelo exercício da democracia (e não no seu dizer, como alerta FREIRE, 1992), favorecendo o domínio da complexidade de processos de produção e de organização do trabalho, pelos profissionais pedagogos.

Outro elemento substantivo em disputa dizia respeito a sujeitos que conquistavam o direito à educação, interditado por tantos anos no texto constitucional e nas políticas públicas: crianças de 0 
a 6 anos; e jovens e adultos não alfabetizados, não escolarizados e/ou com baixa escolarização. Até a Constituição Federal (CF) de 1988, o direito negado a esses sujeitos se fazia acompanhar da formação de professores para um único foco central - os de 7 a 14 anos -, o que na prática significava atender os que acessavam o então ensino de primeiro grau, reservando-se a formação de magistério de nível médio à docência no primeiro segmento desse grau de ensino, e às licenciaturas (de nível superior) a docência no segundo segmento do mesmo grau de ensino. Com a Constituição Federal assegurando o direito de todos à educação independente da idade, não apenas se exigia reorganização das ofertas para atender todos os sujeitos de direito, mas também da formação, que passava a ser requerida em nível superior, desde os anos iniciais do ensino fundamental, como a nova LDBEN se expressava, a partir de 1996. Além disso, principalmente, exigia-se o reconhecimento de novos sujeitos como público do ensino fundamental e médio, o que implicava revisionar os fundamentos da formação de professores, fosse na pedagogia, fosse nas licenciaturas em geral.

A perspectiva do direito de todos à educação se, por um lado, passou a ser uma conquista da cidadania, por outro, desafiadoramente, se impõe ainda hoje à formação de professores - e não apenas nas licenciaturas, mas mesmo no campo da pedagogia. Impõe-se, também, às políticas públicas, cujos compromissos com a demanda potencial são frágeis, fazendo com que um direito careça de proteção no mais das vezes não assegurada pelos que devem zelar pelo cumprimento da CF - os ministérios públicos de estados e municípios, estes, a quem cabe executar políticas de atendimento. Sujeitos de direito, portanto, permanecem interditados da escolarização, e esta, quando ofertada, esbarra nos limites de uma formação precária e insuficiente de professores, do ponto de vista dos fundamentos epistemológicos e teórico metodológicos que atendam especificidades e necessidades do público jovem e adulto.

Diversamente deste público, a oferta aos de quatro a seis anos tem sido a principal bandeira dos poderes municipais, especialmente, e a de zero a três anos vem se acelerando nos últimos tempos, ainda que internamente os sistemas de ensino sofram de problemas crônicos como a repetência e o abandono da escola ${ }^{3}$ por parte do estudante, que em percentagem reduzida consegue concluir o curso.

\footnotetext{
${ }^{3}$ Um grupo de estudiosos, liderados pelo professor Gerson Tavares do Carmo, da Universidade Estadual do Norte Fluminense vem, desde o segundo semestre de 2014, buscando conformar um novo campo de estudos sobre permanência, forma de compreender, mais apropriadamente, o fenômeno da "evasão". Este, muito estudado e pouco compreendido, só tem repetido os mesmos lugares comuns que culpabilizam a vítima, sem avançar no entendimento dos processos que poderiam explicar por que ficam os que permanecem na escola e as razões intraescolares que produzem o chamado fracasso escolar.
} 
No tocante à EJA, outro aspecto a relevar diz respeito ao fato de ela não representar um nível de ensino, mas sim uma modalidade para o ensino fundamental e médio, o que significa um modo próprio de fazer esses dois níveis de ensino, que mantêm equivalência para prosseguimento e circulação de estudos nos sistemas de ensino com/na chamada escola regular destinada a crianças, adolescentes e jovens. Sendo modalidade, a LDBEN (1996) lhe garante no art. $37 \S 1^{\circ}$ o princípio que atende à especificidade dos sujeitos: "oportunidades educacionais apropriadas, consideradas as características do alunado, seus interesses, condições de vida e de trabalho".

Este princípio torna-se ainda mais relevante quando se pensa que os sujeitos estudantes da EJA são, por princípio, trabalhadores que integram a população economicamente ativa (PEA, segundo definição do IBGE para sujeitos a partir de quinze anos). Trabalhadores são todos em idade/condições de produzir a própria existência sem necessitar de um adulto (como no caso de crianças), mesmo que sem emprego ou desempregados; com e sem carteira assinada; empreendedores individuais ou não etc. Essa condição informa que integrantes da coorte de jovens e adultos trabalhadores detêm saberes produzidos no mundo do trabalho, e que a condição de estudantes (porque voltam à escola), sucede-se àquela primeira, e não o contrário. Como então, pensar trabalhadores estudantes como sujeitos da educação de jovens e adultos? Que oferta lhes oferecer?

O que esta consideração alerta é que a denominação usual da escola aos sujeitos, como alunos, passa a ser insuficiente para definir especificidades de seus percursos formativos, pelo fato de esta categoria (alunos) operar com uma certa homogeneidade, bastante discutível em se tratando de um público jovem e adulto trabalhador, com experiências de vida que, em muito, ultrapassam as de crianças.

Adicione-se a isso a diversidade que os conforma, para além da idade: são sujeitos diversos, com questões de gênero e étnico-raciais, que pertencem a classes populares, que são pobres? Moram em localidades distantes e desprovidas de serviços básicos? Têm filhos, netos, arrimam toda uma família? São deficientes, mas hoje conseguem chegar à escola? Talvez moradores do campo, ou talvez pescadores... Como se observa, a diversidade possível entre jovens e adultos é infinita, e ao ser valorizada pela riqueza que comporta pode diminuir a desigualdade que, na nossa sociedade, passou a pautar a diversidade: quanto mais diverso, mais desigual.

Cabe, ainda, considerar que todos que chegam a um curso de formação de professores também eles jovens e adultos - passaram por múltiplas experiências escolares que mais os formaram professores nas experiências do que o próprio curso seria capaz de fazer. Dessas experiências resultam conhecimentos e conteúdos científicos - e crenças, valores, linguagem verbal 
e corporal etc. - com os quais se impõe o diálogo. Assim, concepções teórico metodológicas do curso se basearam na ressignificação do lugar da experiência, no sentido que Larrosa (2002) lhe atribui, para que as aprendizagens ocorram. Carreando a concepção epistemológica de tessitura de conhecimento em rede (ALVES, 2002), não se buscava “outro" modelo curricular (ALVES, 2002, OLIVEIRA, 2004), mas se faria emergir o que era feito/tecido no cotidiano do curso, revelando linhas de força necessárias, que tornassem práticas possíveis a própria formulação conceitual.

Desse modo, o estágio curricular supervisionado também foi campo de disputas: não mais um estágio em que o professor docente acompanha/programa as práticas que os sujeitos "devem" conhecer para "bem se formarem", mas um lugar de vivenciar experiências pedagógicas e sociais expressivas da realidade brasileira, tanto em espaços públicos quanto privados, dependendo dos objetivos das licenciaturas e do bacharelado, produzido pelas possibilidades de cada um compreendê-las. O documento original partia do princípio de que são os estudantes que vão às práticas e o diálogo com as experiências deles se daria pelos relatórios. Em diálogo com o professor orientador de estágio, seus sentidos e significados passariam a emergir. Aquele os acompanharia nos encontros semanais em sala de aula, não indo a campo com os estudantes: a experiência de um professor experiente "ver" a realidade jamais seria igual à de um pedagogo em formação. Portanto, a mediação entre o que estudantes em formação conseguem "ver" e como veem a realidade seria objeto de negociação/diálogo entre sujeitos professor e estudantes, nos limites em que o início de uma trajetória profissional alcança, com permanente curiosidade e busca intelectual de sujeitos que se movem em direção e na aproximação às diversas possibilidades que podem resultar das práticas.

\section{FORMAÇÃO INICIAL EM PEDAGOGIA: FUNDAMENTOS DE UM CURSO - FINALIDADES, CONCEPÇÕES}

A formulação do novo curso de pedagogia teve início em 2000, com outro movimento de revisão e rediscussão curricular, estimulado pelas mudanças visíveis na sociedade e expectativas criadas em torno do novo século e milênio, assim como pela crise de paradigmas e de modos de conhecer que assaltavam os estudiosos, o que exigia rediscutir processos de formação do pedagogo e consequente necessidade de acompanhar o movimento da sociedade e da ciência.

Citam-se alguns marcos desse movimento: a) a atuação da Associação Nacional pela Formação de Profissionais da Educação (Anfope) e do Fórum Nacional de Diretores de Faculdades, Centros de Educação ou Equivalentes das Universidades Públicas Brasileiras (Forumdir), expressos em eventos como o Encontro Nacional de Didática e Prática de Ensino (Endipe), a Reunião Anual 
da Associação Nacional de Pós-Graduação e Pesquisa em Educação (ANPEd), ${ }^{4}$ atuação dos Fóruns de EJA (já espalhados em muitos estados do país, à época), em defesa da base comum na Pedagogia e na licenciatura: de que todos os professores são educadores, e a docência definia-se como fundamento da identidade profissional do educador; b) a pós-graduação e a pesquisa em educação iniciam e desenvolvem compreensão mais complexa do cotidiano escolar, exigindo mais nitidez dessa perspectiva na graduação; c) no campo da EJA, mesmo com reservas, o Brasil assinara em Hamburgo a Declaração final da V Confintea e a Agenda para o Futuro e via, em maio de 2000, a homologação do Parecer CEB/CNE n. 11 e da Resolução 01 a ele correspondente; d) acordos assinados durante a década de 1990 pelos países membros da ONU direcionando-se ao novo século e milênio, com expectativas de todas as áreas sobre a educação continuada e o aprender por toda a vida, assim como pelo direito à aprendizagem dos deficientes, definido pela Declaração de Salamanca sobre Princípios, Política e Prática em Educação Especial (UNESCO, jun. 1994); e) o tema da diversidade, da inclusão, em pauta, que buscavam vencer as barreiras da desigualdade e, especificamente na metrópole, o empobrecimento das populações, segregadas em comunidades tomadas pela violência armada, que vivia a capitulação do poder público; f) novas epistemologias nos processos de conhecimento se consolidando - concepções de redes de conhecimento e de transdisciplinaridade, alterando modelos explicativos até então adotados; g) ações afirmativas para cotas raciais e alunos de escola pública chegando por via legal à UERJ, confirmando um direito e ampliando o perfil de estudantes já bastante habitual nos cursos de pedagogia; h) avaliações internas à Faculdade de Educação, apontando críticas e necessidade de mudanças em relação a expectativas de estudantes de pedagogia.

Não eram poucos os marcos referenciais que nos balizavam. Mas um desafio interno ainda havia de ser enfrentado: a existência longa de um outro curso de formação de professores, que coabitava a Faculdade de Educação durante o mesmo período, sob outra coordenação, com vestibular diverso. Como proceder? Quais os possíveis vínculos nos percursos da formação?

Os campos de investigação e produção acadêmica de algumas linhas de pesquisa também punham em cheque concepções curriculares, dimensões formativas do professor, e exigiam uma qualificação do pedagogo que incluía seu estar/fazer/transformar o mundo, entendido pela ação cultural que se exerce sobre a realidade.

Com todas essas referências, surgia a defesa da formação incluindo, em um mesmo processo, licenciatura e bacharelado em torno de quatro eixos comuns. Esses eixos - transversais a

\footnotetext{
${ }^{4}$ À ocasião a Reunião da ANPEd era anual, o que se modificou a partir de 2015, quando se iniciou a bienalidade.
} 
todo o curso - possibilitavam a integração de conhecimentos e práticas desenvolvidos em atividades dentro e fora das salas de aula, em todos os espaços/tempos da Universidade e da comunidade externa. São eles: a) pedagogia nas instituições, com ênfase em processos pedagógicos desenvolvidos no âmbito de instituições e demais entidades públicas e privadas; b) pedagogia nos movimentos sociais, com ênfase em processos educativos de movimentos sociais populares; c) educação escolar, com ênfase em processos pedagógicos realizados nas escolas públicas para sujeitos crianças, jovens e adultos; d) educação inclusiva, com ênfase na integração social e pedagógica de pessoas com necessidades educativas especiais, atravessando todos os componentes curriculares.

O percurso formativo, representado por um retângulo transversalizado por uma diagonal e dividido em oito colunas - os oito períodos semestrais -, demonstrava, no triângulo retângulo superior, o conjunto de disciplinas de licenciatura; e no triângulo retângulo inferior as do bacharelado. À medida que se percorriam os períodos, reduziam-se as disciplinas da licenciatura e ampliavam-se as do bacharelado.

O bacharelado - em pedagogia nas instituições e nos movimentos sociais -, em síntese, constituía um largo campo de formação do pedagogo, com base na concepção de aprender em espaços sociais para além da escola: em atuação em movimentos sociais, em demais instituições, na prática social, em projetos socioambientais; em práticas de trabalho; de ONGs; concebendo fundamentos e abordagens pedagógicas na EJA em todas as possíveis áreas em que se aprende na sociedade.

Observe-se que não se trata de uma pedagogia das instituições e dos movimentos sociais, mas nas: a diferença, aparentemente sutil, entretanto, carreia sentidos bem diversos: entende-se que o pedagogo leva, à prática, a teoria para (re)fazer a prática, e não se filia a qualquer concepção prévia existente nesses espaços (muitas vezes ideológica, sem fundamentos conceituais, como a de treinamento, por exemplo, em empresas). Assim, o pedagogo passa a ser o responsável por pensar e propor - com base epistemológica e teórico metodológica das ciências que conformam o campo da educação e do conhecimento de que precisa dispor sobre a diversidade dos sujeitos - a forma mais adequada de intervenção e de organização de processos de aprendizagem para sujeitos trabalhadores, militantes etc.

Componentes curriculares, por exigência institucional, mantiveram a denominação de “disciplinas", embora estivessem fecundados por concepções mais complexas do que as que sustentavam essas últimas, possibilitando nova organização que permitia dar visibilidade ao que antes estava submerso. Essa compreensão definiu, então, campos organizadores do conhecimento, 
intimamente vinculados à história da Faculdade de Educação em relação com a história dessa formação no país, na região e na Universidade: o passado vivido, o futuro exigido, explicitados como necessidade e possibilidade.

Assim, a licenciatura inflexionava uma vez mais a formação docente ${ }^{5}$ - como prática de ensinaraprender a crianças, jovens e adultos -, por se fazer como ação pedagógica pensada a partir de sujeitos de direito à aprendizagem. Garantia-se, desse modo, a formação de professores como representantes do Estado e cumpridores do dever que a ele cabe, na garantia do direito à educação para todos, independente da idade, nos termos definidos pela Constituição Federal e regulado por leis ordinárias, entre elas a LDBEN (1996). Assim, as metodologias de ensino da história, geografia, ciências, matemática enunciavam os sujeitos a quem se destinavam: para crianças, jovens e $\operatorname{adultos}^{6}$; em alfabetização e formação de leitores também eram os sujeitos que guiavam a concepção adotada. $\mathrm{O}$ mesmo se repetia para os fundamentos: todos dever-se-iam voltar para pensar características dos sujeitos segundo gênero, faixa etária, condição étnico-racial etc.

Como forma de tornar o currículo uma prática, o componente Pesquisa e Práticas Pedagógicas (PPP) permeava seis períodos do curso, tematicamente, levando os estudantes - nos dois últimos períodos - à proposição e desenvolvimento de projeto e monografia de final de curso; sem enrijecer o percurso, previa-se a possibilidade de o estudante trocar de PPP por duas vezes durante a sequência, do mesmo modo culminando com monografia I e II nos $7^{\mathrm{o}}$ e $8^{\mathrm{o}}$ períodos. Ganhava relevância a pesquisa relacionada à prática pedagógica, exigindo a formulação de como se daria nas duas formações desenvolvidas - licenciatura e bacharelado. Que aproximações e diferenças, seguindo princípios da educação inclusiva? Também norteou o caminho que se intentava percorrer, o rumo de concepções postas em documentos construídos em debates e discussões em torno de diretrizes para a pedagogia, que configurava o profissional desse campo como professor; organizador e gestor do sistema educacional; e pesquisador.

As dez disciplinas eletivas integrantes do desenho curricular foram pensadas como componentes do curso, sujeitas - pela escolha - ao interesse dos estudantes, que elegeriam um campo de atuação. Por elas poderiam aprofundar estudos nesse campo, compensando a formação mais generalista do curso, com quatro áreas de formação. O estágio supervisionado, originalmente

\footnotetext{
${ }^{5}$ Fazemos alusão ao momento anterior (1991) em que a Faculdade de Educação já organizara o curso de pedagogia pela oferta de campos de conhecimento que tomavam em conta a diversidade de sujeitos de direito.

${ }^{6}$ A denominação passava a ser Metodologia do Ensino da História para crianças, jovens e adultos; Metodologia do Ensino da Matemática para crianças, jovens e adultos etc. Com isso não se admitia que havia uma e apenas uma opção metodológica para realizar o ensino nos campos de conhecimento, mas que todas elas se organizavam tendo em vista os sujeitos a quem se destinavam, segundo suas especificidades e requerimentos próprios.
} 
com 720h, se organizava em dois semestres para cada área: educação infantil; anos iniciais do EF para crianças, jovens e adultos; e em pedagogia nas instituições e nos movimentos sociais. ${ }^{7}$ Nas duas primeiras áreas o locus central era a instituição escola. Na área de pedagogia nas instituições $e$ nos movimentos sociais as instituições eram múltiplas e variadas, e apenas a escola não estaria contemplada, porque a ela se destinava toda a formação para a escolarização. Propunha-se ${ }^{8}$ que no estágio I os estudantes conhecessem, no mínimo, três experiências diversas de intervenção pedagógica em escola/instituições/movimentos diferentes. No estágio II o estudante elegeria uma das escolas/instituições/movimentos e aprofundaria o conhecimento de práticas ali realizadas. Ou seja, o estágio I, em cada área de atuação, destinava-se a explorar o campo de um futuro professor/pedagogo - na instituição escola e/ou em outros espaços/instituições/movimentos da prática social; o estágio II, em cada área de atuação, aprofundaria o conhecimento sobre uma instituição escola e/ou outro espaço/uma das instituições/movimentos já conhecidos — a que mais lhe interessasse como campo de atuação profissional.

O novo curso de pedagogia definia, assim, o profissional que visava a formar: a) o professor para os anos iniciais do ensino fundamental de crianças, jovens e adultos em contextos livres ou de privação de liberdade; b) o professor para crianças de 0 a 6 anos (da educação infantil); c) o professor que lida com crianças, jovens e adultos com necessidades educativas especiais; d) o pedagogo que desenvolve projetos pedagógicos em instituições educativas (ONGs, conselhos tutelares, autarquias, movimentos populares, igrejas etc.), em ações coletivas e culturais com crianças e jovens em conflito com a lei; em instituições governamentais diversas; em organismos públicos e empresas estatais; em instituições privadas.

\section{O CAMPO DA EJA: ALARGAMENTO DE CONCEPÇÃO}

A formação de pedagogos para a área da educação de jovens e adultos, nesse desenho, sem dúvida, tem seu campo de possibilidades alargado, e é sempre uma surpresa para os jovens que chegam até a Faculdade de Educação descobrir um universo de escolhas jamais imaginado para a área. Muitas frentes abrem-se para a atuação de nossos graduados, e destacaria o trabalho pedagógico em museus de arte, de ciências, botânico/zoológico. Sem dúvida esses são campos que

\footnotetext{
${ }^{7} \mathrm{Na}$ mudança de carga horária da pedagogia, feita por ato do Conselho Nacional de Educação, algum tempo depois da implantação do primeiro desenho, passou-se a estabelecer internamente 360h (das 300h mínimas admitidas pelo parecer), acrescendo um campo de estágio: instituições de formação para o magistério em nível de ensino médio. Cada campo restou com $90 \mathrm{~h}$ de estágio supervisionado, mas sem reorganizar objetivos e modos de atuar em cada um.

${ }^{8}$ A proposta de estágios se organizou por meio de um documento norteador produzido coletivamente, tão logo o curso foi implantado, considerando que o início dos estágios só começaria a partir do quarto período.
} 
estendem a formação para a perspectiva da educação continuada, do aprender por toda a vida, verdadeiro sentido da educação de jovens e adultos.

Essa afirmação vem da compreensão de que a EJA, pós-V Confintea, organiza-se, entre nós, em duas vertentes fundamentais: a primeira, a da escolarização, para cumprir o dever da oferta a cidadãos de direito (observe-se em dados do IBGE, 2010, o quadro dos não escolarizados no país e busque-se comparar tomando em conta algum levantamento existente sobre o número de cursos de pedagogia com formação em EJA); a segunda, a vertente da educação continuada e o conjunto de significados que pode abarcar: desde organizações coletivas de sujeitos em torno de temáticas de interesse (gênero, educação ambiental etc.) ou de luta social e política (defesa de patrimônios ambientais, genéticos, qualidade de vida etc.); à formação em geral de trabalhadores para atuação no mundo do trabalho (formação específica para determinadas funções etc.); ao destaque necessário à formação continuada de professores, esses também jovens e adultos em processos continuados de formação e aprendizado.

Muitos são os marcos internacionais e nacionais que vêm orientando políticas públicas e, sem dúvida, (re)definindo o campo e os espaços de atuação do pedagogo, dos quais não se pode deixar de relevar, por exemplo, os sentidos que políticas de ação afirmativa conformaram para o campo da EJA.

\section{CONSIDERAÇÕES FINAIS COMO DESAFIOS DA PRÁTICA CURRICULAR: DA CONCEPÇÃO À PRÁTICA - DISTANCIAMENTOS E AUSÊNCIAS}

Vários ajustes foram sendo feitos, depois de aprovado o curso não apenas internamente pelas instâncias definidoras de política acadêmica, mas também como exigência do Conselho Estadual de Educação, para quem a releitura do Parecer CNE 05/2005 e Parecer 03/2006 apontava para um visão estreitada da formação do pedagogo que não admitia a autonomia da universidade para formar, nesse campo, um bacharel. Depois de muitas idas e vindas, um recuo estratégico foi necessário, para que se titulassem os formandos, todos com pendências pela não aprovação do curso pelo CEE do estado e carecendo do título para que pudessem fazer prova nos inúmeros concursos a que tiveram êxito, em secretarias de estado e municipais de educação. Várias versões foram sendo produzidas sobre o curso e, especialmente a que reduziu a carga horária de estágio produziu forte impacto sobre a concepção aqui apresentada, por praticamente superpor algumas disciplinas até quase fazê-la perder o sentido epistemológico que lhe deu origem. Este, um dos problemas que o curso sofreu, mas não o único. 
A concepção ainda vigente, regra geral, é mais ou menos a originalmente pensada e formulada, embora nunca se tenha conseguido: a) manter a oferta de PPP como pensado, ou seja, como grupos de pesquisa coletivos, com estudantes de todos os períodos, em diálogo e percursos formativos com objetivos próprios, mas em interação horizontalizada; b) discutir o fazer pedagógico cotidiano do curso (o que deveria ser feito como centro de estudos em tardes de um dia da semana, quando em tese todos os professores estariam atuando com PPPs; c) manter professores novos afinados com as concepções descritas (e também muitos dos antigos, que não participaram das discussões de reformulação curricular); d) alargar a oferta de eletivas/obrigatórias universais a serem oferecidas a estudantes de licenciaturas em geral; e) alterar a distribuição diária de horários de aulas e, consequentemente, o número de períodos do curso.

Algumas certezas se agigantam e não são mais possíveis de se manterem ocultadas, em lugares subalternizados, já que sua constatação deve servir para corrigir rumos e aperfeiçoar a proposta de formação. Mesmo reconhecendo-se qualidades e atributos à proposta vigente, é inegável a necessidade de revisioná-la, o que se faz por força de exigência do Conselho Estadual de Educação/RJ, além de determinações posteriores trazidas pela Resolução CNE 02, de 1 jul. 2015, ${ }^{9}$ cujo prazo máximo está fixado para meados de 2017. Portanto, o processo de reformulação curricular encontra-se em curso, envolvendo professores e alunos, não apenas da pedagogia, mas agora de todas as licenciaturas da Universidade. Em favor dessa exigência, destaca-se que mais de dez anos se passaram, o que impunha repensar o curso, pondo-o sob lentes que o examinassem em detalhes, e sob dispositivos que, escavando seus fazeres, pudessem revelar surpresas que alimentassem os que desejam protagonizar um outro momento de revisão do fazer da formação docente inicial.

Assim, algumas perguntas sintetizam esse momento e guiam as decisões a serem tomadas:

1) a concepção do curso ainda é adequada ao momento presente, do ponto de vista epistemológico, de ruptura com determinados paradigmas de conhecimento, e na forma como organizou o fluxo disciplinar?

2) deve-se manter o curso em oito semestres letivos e com toda a carga horária $(\mathrm{CH})$ que comporta, ou é possível criar um núcleo central que não se perde, eliminando redundâncias e detalhamentos excessivos nele observados?

\footnotetext{
${ }^{9}$ Define as Diretrizes Curriculares Nacionais para a formação inicial em nível superior (cursos de licenciatura, cursos de formação pedagógica para graduados e cursos de segunda licenciatura) e para a formação continuada.
} 
3) é possível voltar ao desenho original de pesquisa e práticas pedagógicas (PPP) para que o curso tenha um caráter mais prático e não apenas teórico?

4) de que modo tecnologias podem ajudar na oferta e desenvolvimento de um curso mais dinâmico e ativo, por parte dos estudantes? Como consegui-lo?

5) com que concepção de currículo estruturaremos a reformulação que se deve promover?

E, por fim, embora não menos relevante, que conformação terá o campo da EJA nesse novo desenho, tendo em vista todas as perguntas anteriores e muitas constatações que ainda demandam levantamentos e inventários de professores e estudantes implicados com a reformulação?

O momento atual exige de docentes e estudantes de Pedagogia novas reflexões sobre o curso, visando à garantia do reconhecimento, mas principalmente coerência de concepções, epistemologias e organizações de percursos formativos em tensão criativa com os campos para os quais se formam professores, especificamente o da educação de jovens e adultos, pela natureza comum de uns e outros sujeitos que se põem em interação.

O curso de pedagogia da Faculdade de Educação, como proposição, teve/tem muitas virtudes: coerência, fundamentos epistemológicos bem definidos, concepção integral de formação, foco nas múltiplas singularidades dos sujeitos, sintonia com a demanda social por professores e gestores pedagógicos. Mas esses reconhecimentos não bastam. O êxito de uma proposta como essa depende, fundamentalmente da prática, das formas como é tomada como objeto de conhecimento e de produção de novos constructos sobre o que significa formar pedagogos. A previsão de avaliação desde a implantação do curso foi descrita no projeto, mas fragilmente tem sido realizada, carecendo de diversas ações regulares em reuniões de estudo e discussão das práticas realizadas pelos docentes do curso. Esforços isolados vêm sendo feitos, em reflexões como esta, e outras apresentadas por companheiros em eventos aqui e ali. Mas que não bastam, porque a compreensão desses fazeres vis$\grave{a}$-vis com a teorização exige rigorosidade ética, disciplina intelectual, aprofundamento conceitual sistemáticos.

A sinalização de que um curso não se faz apenas com uma eficiente formulação, mas na prática cotidiana, e que essa prática exige permanente estudo, troca de experiências, discussões, divergências, aproximações foi vigorosa desde o início das atividades de repensar o curso em andamento, sem que, no entanto, conseguisse ser consolidada como um projeto de fato da Faculdade de Educação.

A formação de pedagogos, por fim, tem imperativos éticos que transcendem o fazer formativo, os questionamentos cotidianos e as inquietações constantes, porque põe em alerta os 
praticantespensantes que a realizam para a questão de que os que formam os pedagogos também se formam nas práticas de formação. 


\section{REFERÊNCIAS}

ALVES, Nilda. Tecer conhecimento em rede. In: ALVES, Nilda, GARCIA, Regina Leite (org.). O sentido da escola. Rio de Janeiro: DP\&A, 2002. p. 111-120.

BRASIL. Constituição federal. Brasília: Congresso Nacional, 5 out. 1988.

. Lei de Diretrizes e Bases da Educação Nacional n. 9394/96. Brasília, 20 dez. 1996.

. Conselho Nacional de Educação. Parecer CEB n. 11/2000. Diretrizes Curriculares para a Educação de Jovens e Adultos. Brasília: MEC, maio 2000.

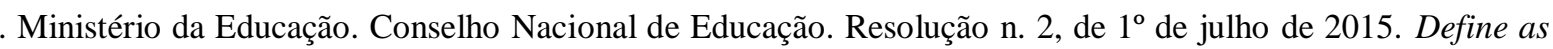
Diretrizes Curriculares Nacionais para a formação inicial em nível superior (cursos de licenciatura, cursos de formação pedagógica para graduados e cursos de segunda licenciatura) e para a formação continuada. Brasília: CNE: MEC, 2015.

FREIRE, Paulo. Pedagogia da esperança. Um reencontro com a Pedagogia do Oprimido. Rio de Janeiro: Paz e Terra, 1992.

LARROSA, Jorge Bondía. Nota sobre a experiência e o saber de experiência. p. 20-28. In: Revista Brasileira de Educação. n. 19. Rio de Janeiro: ANPEd, jan./fev./mar./abr. 2002.

OLIVEIRA, Inês Barbosa de, PAIVA, Jane (Orgs.). Educação de Jovens e Adultos. Rio de Janeiro: DP\&A, 2004. p. 101-110.

PAIVA, Jane. Programa UERJ de formação de professores para a educação básica: a reformulação do curso de pedagogia da Faculdade de Educação. Rio de Janeiro: Faculdade de Educação: UERJ, set. 2002. 48p. (mimeo).

Concepções, normas e procedimentos de estágio curricular supervisionado. Rio de Janeiro: Faculdade de Educação: XXXX, out. 2005. 23p. (mimeo.).

UNESCO. Declaração de Hamburgo sobre a Educação de Adultos e Plano de Ação para o Futuro. V Conferência Internacional sobre Educação de Adultos. Hamburgo, Alemanha, 14-18 jul. 1997.

Declaração de Salamanca. Sobre Princípios, Políticas e Práticas na Área das Necessidades Educativas Especiais. Conferência Mundial sobre Educação Especial. Salamanca, Espanha, 7-10 jun. 2014. 


\section{RESUMO}

O artigo problematiza concepção de currículo de formação como produção cotidiana, e decorre de práticas de formação inicial de professores para os anos iniciais do EF e múltiplos espaços sociais e educativos, enfatizando jovens e adultos, público para quem também se destinava. Implantada no curso de Pedagogia da Faculdade de Educação da Universidade do Estado do Rio de Janeiro (UERJ) desde 2003, a concepção adotada guardava coerência com diretrizes de movimentos de formação, disputadas na arena das políticas públicas, avançando epistemologicamente no fazer da formação. A resultante fundamentava-se na experiência formadora de 13 anos em que a EJA representava um campo definido da formação, ao lado da educação infantil e da educação especial, associado, cada um deles, à formação do professor para o curso de magistério em nível médio.

Palavras-chave: formação de professores; formação para a EJA; currículo de pedagogia; currículo como produção cotidiana

\section{FROM THE CONCEIVING TO THE PRACTICE IN INITIAL FORMATION: YOUNG AND ADULT EDUCATION IN THE PEDAGOGY CURRICULUM}

\section{ABSTRACT}

The article problematizes the conception of the formation curriculum as an everyday production, and stems from the practices of initial teachers' formation for elementary school and multiple educational and social spaces, emphasizing young and adults, also its target audience. Deployed in the Pedagogy Course of State University of Rio de Janeiro's (UERJ) Education College in 2003, the adopted conception kept coherence with formation movements' guidelines, disputed at the arena of public policies, epistemologically advancing in the making of formation. The resultant was based in the formation experiences of 12 years, in which Young and Adult Education represented a defined field in formation, beside childhood education and special education, associated, each of them, with the formation of the teacher in the course of high school-level education.

Keywords: Teacher formation; Young and Adult Education formation; pedagogy curriculum; curriculum as an everyday production.

Submetido em Jan. 2016 Aprovado em Jun. 2016 